\title{
Proteomic Analysis of the Vitreous following Experimental Retinal Detachment in Rabbits
}

\author{
Nakul Mandal, ${ }^{1}$ Geoffrey P. Lewis, ${ }^{2}$ Steven K. Fisher, ${ }^{2,3}$ Steffen Heegaard, ${ }^{4,5}$ \\ Jan U. Prause, ${ }^{5}$ Morten la Cour, ${ }^{4}$ Henrik Vorum, ${ }^{6}$ and Bent Honoré ${ }^{7}$ \\ ${ }^{1}$ Department of Ophthalmology, Lund University, 22185 Lund, Sweden \\ ${ }^{2}$ Neuroscience Research Institute, University of California, Santa Barbara, Santa Barbara, CA 93106-5060, USA \\ ${ }^{3}$ Department of Molecular, Cellular and Developmental Biology, University of California, Santa Barbara, \\ Santa Barbara, CA 93106-9625, USA \\ ${ }^{4}$ Department of Ophthalmology, University of Copenhagen, 2600 Glostrup, Denmark \\ ${ }^{5}$ Eye Pathology Institute, University of Copenhagen, 2100 Copenhagen, Denmark \\ ${ }^{6}$ Department of Ophthalmology, Aalborg University Hospital, 9000 Aalborg, Denmark \\ ${ }^{7}$ Department of Biomedicine, Aarhus University, 8000 Aarhus, Denmark
}

Correspondence should be addressed to Nakul Mandal; nm@doctors.org.uk

Received 14 June 2015; Revised 17 October 2015; Accepted 19 October 2015

Academic Editor: Ciro Costagliola

Copyright (C) 2015 Nakul Mandal et al. This is an open access article distributed under the Creative Commons Attribution License, which permits unrestricted use, distribution, and reproduction in any medium, provided the original work is properly cited.

Purpose. The pathogenesis of rhegmatogenous retinal detachment (RRD) remains incompletely understood, with no clinically effective treatment for potentially severe complications such as photoreceptor cell death and proliferative vitreoretinopathy. Here we investigate the protein profile of the vitreous following experimental retinal detachment using a comparative proteomic based approach. Materials and Methods. Retinal detachment was created in the right eyes of six New Zealand red pigmented rabbits. Sham surgery was undertaken in five other rabbits that were used as controls. After seven days the eyes were enucleated and the vitreous was removed. The vitreous samples were evaluated with two-dimensional polyacrylamide gel electrophoresis and the differentially expressed proteins were identified with tandem mass spectrometry. Results. Ten protein spots were found to be at least twofold differentially expressed when comparing the vitreous samples of the sham and retinal detachment surgery groups. Protein spots that were upregulated in the vitreous following retinal detachment were identified as albumin fragments, and those downregulated were found to be peroxiredoxin 2, collagen-I $\alpha 1$ fragment, and $\alpha$-1-antiproteinase F. Conclusions. Proteomic investigation of the rabbit vitreous has identified a set of proteins that help further our understanding of the pathogenesis of rhegmatogenous retinal detachment and its complications.

\section{Introduction}

Rhegmatogenous retinal detachment (RRD) is characterized by the accumulation of subretinal fluid between the neurosensory retina and retinal pigment epithelium following the formation of a retinal break [1]. The pathogenesis of RRD is complex and incompletely understood, involving age-related and/or inherited structural and molecular changes of the vitreous extracellular matrix and vitreoretinal interface, and the process of posterior vitreous detachment [2]. The annual incidence of the condition has been estimated at 12.05 per 100,000 , and although primary surgical reattachment is successful in the great majority of cases, photoreceptor cell death, subretinal fibrosis, and proliferative vitreoretinopathy (PVR) continue to be significant causes of reduced visual outcomes $[3,4]$.

PVR involves the proliferation and migration of various cell types including retinal pigment epithelial (RPE) cells, Müller cells, inflammatory cells, and hyalocytes, which contribute to the formation of vitreal and periretinal membranes that can impede photoreceptor regeneration following surgical reattachment and cause tractional retinal detachment. The postulated epithelial-to-mesenchymal transition of RPE cells and Müller cell activation and growth onto the retinal surfaces are believed to be pivotal events in PVR [4, 5]. It appears that the exposure of such cells to the vitreous and associated 
growth factors as a result of RRD significantly contributes to the pathogenesis of PVR, though the basic cause as well as a clinically effective therapeutic approach for this condition remains elusive $[5,6]$.

Proteomics studies proteins on a large scale in pursuit of a global and integrated view of disease processes at the protein level, which may potentially lead to the identification of novel biomarkers and therapeutic targets useful in clinical practice [7-11]. RRD would likely be associated with alterations in the proteomic profiles of both the retina and vitreous. Indeed, we initially undertook the first such retinal study from which a number of potentially important proteins were identified [12]. The present study extends the proteomic investigation to the vitreous of this rabbit model of retinal detachment, building upon previous such analyses of human vitreous [13-16], in order to add further knowledge of the underlying pathophysiology $[10,17]$.

\section{Materials and Methods}

2.1. Retinal Detachment Surgery. Inferior retinal detachment was created in the right eyes of six New Zealand red pigmented rabbits. The eyes were normal with no evidence of disease on examination. Combined injections of xylazine $(6.7 \mathrm{mg} / \mathrm{kg})$ and ketamine $(33.3 \mathrm{mg} / \mathrm{kg})$ were administered intramuscularly to induce anesthesia and analgesia. The pupils were dilated with topical drops of atropine and tropicamide ( $1 \%$ solutions). A pipette tip, with an external diameter of approximately $100 \mu \mathrm{m}$, was inserted into the eye through a pars plana incision. Sodium hyaluronate (Healon, $0.25 \%$ in a balanced salt solution; Pharmacia, Piscataway, NJ) was infused via a glass pipette between the neurosensory retina and retinal pigment epithelium. Healon was necessary to prevent spontaneous retinal reattachment, and $0.25 \%$ is the most dilute solution that maintains the detachment for extended periods. Approximately $50 \%$ of the retina beneath the medullary rays, which included the central retina, was detached (Figure 1). Sham surgery was performed in the right eyes of five other rabbits that were used as controls, which involved surgical entry of the vitreous cavity without disruption of the retina. Scleral incisions were closed with 8-0 nylon suture. Seven days postoperatively the animals were euthanized by the administration of sodium pentobarbital $(120 \mathrm{mg} / \mathrm{kg}$; Butler Schein, Dublin, $\mathrm{OH}$ ) and the eyes enucleated. After removal of the cornea and lens, the associated vitreous of the sham and detached retinas was extracted and immediately snap-frozen in liquid nitrogen within separate vials. There was no gross evidence of blood or other contamination of the vitreous samples at the time of tissue harvesting. The vitreous samples were stored at $-80^{\circ} \mathrm{C}$ until further use.

All of the animal experiments undertaken in this study were in accordance with the standards of the National Institutes of Health Animal Care and Use Committee protocols, the ARVO Statement for the Use of Animals in Ophthalmic and Vision Research, and the guidelines of the Animal Resource Center, University of California, Santa Barbara.

2.2. Protein Extraction. The rabbit vitreous samples were homogenized and dissolved in a lysis buffer containing $9 \mathrm{M}$

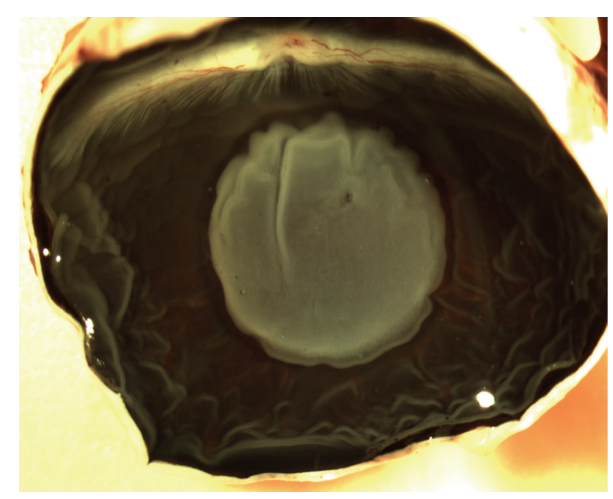

FIgURE 1: Appearance of the retinal detachment in the rabbit eye at seven days. The area of detached retina beneath the medullary rays appears grey and is surrounded by the darker attached retina. The detached retina contains a small hole where the micropipette was inserted. The retinal folds in the periphery occurred during the removal of the anterior structures.

urea, 2\% (v/v) Triton X-100, 2\% (v/v) immobilized pH gradient (IPG) buffer ( $\mathrm{pH} 3-10$ nonlinear), and 2\% (w/v) dithiothreitol (DTT). The total protein content in each vitreous sample was determined with Non-Interfering Protein Assay (Calbiochem, San Diego, CA). The protein samples were stored at $-80^{\circ} \mathrm{C}$ until further use.

2.3. Two-Dimensional Gel Electrophoresis. The extracted proteins were first fractionated by isoelectric focusing (IEF) using pH 3-10 nonlinear $18 \mathrm{~cm}$ IPG strips (GE Healthcare, Chalfont St. Giles, Buckinghamshire, UK). The IPG strips were rehydrated for $20 \mathrm{~h}$ at room temperature in $200 \mu \mathrm{L}$ lysis buffer each containing $20 \mu \mathrm{g}$ protein from individual vitreous samples and $150 \mu \mathrm{L}$ rehydration buffer $(8 \mathrm{M}$ urea, $2 \%(\mathrm{w} / \mathrm{v})$ 3-[(3-cholamidopropyl)dimethylammonio]-1-propanesulfonate (CHAPS), $0.3 \%(\mathrm{w} / \mathrm{v})$ DTT, and $2 \%(\mathrm{v} / \mathrm{v})$ IPG buffer), using the Immobiline DryStrip Reswelling Tray (GE Healthcare). The IEF was undertaken on a Multiphor II Electrophoresis System (GE Healthcare) at $500 \mathrm{~V}$ for $5 \mathrm{~h}$ and $3500 \mathrm{~V}$ in two steps for $5 \mathrm{~h}$ and $9.5 \mathrm{~h}$ in a gradient mode at $17^{\circ} \mathrm{C}$ with the use of a MultiTemp III Thermostatic Circulator (GE Healthcare). Before the second-dimension sodium dodecyl sulfate (SDS) polyacrylamide gel electrophoresis (PAGE), the IPG strips were equilibrated firstly for $10 \mathrm{~min}$ with gentle agitation in $20 \mathrm{~mL}$ of equilibration solution $(0.6 \%(\mathrm{w} / \mathrm{v})$ Tris$\mathrm{HCl}, \mathrm{pH}$ 6.8, $6 \mathrm{M}$ urea, 30\% (v/v) glycerol, $1 \%$ (w/v) SDS, and $0.05 \%(\mathrm{w} / \mathrm{v})$ DTT) and secondly using $4.5 \%(\mathrm{w} / \mathrm{v})$ iodoacetamide and bromophenol blue. The IPG strips were then transferred to $12 \%$ polyacrylamide gels for electrophoresis, which was performed at a maximum voltage of $50 \mathrm{~V}$ for approximately $20 \mathrm{~h}$ to separate the proteins vertically on the basis of molecular mass.

2.4. Protein Staining. The two-dimensional (2D) gels were silver stained using a protocol optimized for protein identification with mass spectrometry [18]. In brief, the gels were fixed overnight in $50 \%(\mathrm{v} / \mathrm{v})$ ethanol, $12 \%(\mathrm{v} / \mathrm{v})$ acetic acid, and $0.0185 \%(\mathrm{v} / \mathrm{v})$ formaldehyde. The gels were washed 3 times 
for $20 \mathrm{~min}$ in $35 \%(\mathrm{v} / \mathrm{v})$ ethanol and pretreated for $1 \mathrm{~min}$ in $0.02 \%(\mathrm{w} / \mathrm{v}) \quad \mathrm{Na}_{2} \mathrm{~S}_{2} \mathrm{O}_{3} \cdot 5 \mathrm{H}_{2} \mathrm{O}$. They were then rinsed in water and stained for $20 \mathrm{~min}$ in $0.2 \%(\mathrm{w} / \mathrm{v}) \mathrm{AgNO}_{3}$ and $0.028 \%(\mathrm{v} / \mathrm{v})$ formaldehyde. Following further rinsing with water, development was undertaken for approximately 3 min in 6\% (w/v) $\mathrm{Na}_{2} \mathrm{CO}_{3}, 0.0185 \%$ (v/v) formaldehyde, and $0.0004 \%(\mathrm{w} / \mathrm{v}) \mathrm{Na}_{2} \mathrm{~S}_{2} \mathrm{O}_{3} \cdot 5 \mathrm{H}_{2} \mathrm{O}$. The development was arrested in a fixative solution of $40 \%(\mathrm{v} / \mathrm{v})$ ethanol and $12 \%(\mathrm{v} / \mathrm{v})$ acetic acid. The $2 \mathrm{D}$ gels were then dried between cellophane sheets and sealed in plastic envelopes.

2.5. Image Analysis. Silver stained 2D gels were scanned on a GS-710 Calibrated Imaging Densitometer (Bio-Rad, Hercules, CA) using the Quantity One program (Bio-Rad), and the PDQuest software (Bio-Rad) was used to define, quantify, and match the protein spots on each of the 2D gels. All well-defined protein spots that were at least twofold (MannWhitney $U$ test, $p<0.05)$ differentially expressed between the sham and retinal detachment vitreous groups were selected for identification with nanoliquid chromatographyelectrospray ionization tandem mass spectrometry (LC$\mathrm{MS} / \mathrm{MS})$.

2.6. Protein Identification. The $2 \mathrm{D}$ gels were removed from their plastic envelopes and rehydrated in water. The selected protein spots were carefully excised from the gels with a scalpel and subjected to in-gel digestion with Trypsin Gold (Mass Spectrometry Grade; Promega, Madison, WI). The peptide samples that were obtained were analyzed by LCMS/MS as previously described [12]. In brief, peptides generated by trypsin digestion were separated on an inert nanoLC system (LC Packings, San Francisco, CA) connected to a Q-TOF Premier mass spectrometer (Waters, Milford, MA). The MassLynx 4 SP4 (Waters) was used to obtain spectra and the raw data was processed using ProteinLynx Global Server 2.1 (Waters). The processed data were used to search the total part of the Swiss-Prot database using the online version of the Mascot MS/MS Ions Search facility (Matrix Science, Ltd.). The search was undertaken with doubly and triply charged ions with up to two missed cleavages, a peptide tolerance of $50 \mathrm{ppm}$, one variable modification, carbamidomethyl-C, and a MS/MS tolerance of $0.05 \mathrm{Da}$. Contaminating peptides such as trypsin, keratin, bovine serum albumin, and all peptides originating from previous samples were disregarded. At least one "bold red" (Matrix Science Ltd., http://www .matrixscience.com/) peptide match was required in the search for protein hits. Individual peptide ions scores above approximately 36 indicated identity or extensive homology giving a less than $5 \%$ probability that the observed match was a random event. All peptides for the protein hits are reported (Table 1).

2.7. Western Blotting. In each case three micrograms of vitreous sample protein was separated on Novex 10-20\% gradient Tris-Glycine polyacrylamide gels (Invitrogen Corporation, Carlsbad, CA) and subsequently transferred to nitrocellulose Hybond-C Extra membranes (GE Healthcare). The membranes were blocked overnight with $5 \%$ skimmed milk in $80 \mathrm{mM} \mathrm{Na} \mathrm{HPO}_{4}, 20 \mathrm{mM} \mathrm{NaH} \mathrm{PO}_{4}, 100 \mathrm{mM} \mathrm{NaCl}$, and
0.05\% Tween 20 buffer, $\mathrm{pH}$ 7.5. Membranes were incubated with anti-albumin (Genway Biotech, CA, USA; 1:5000) and anti-peroxiredoxin 2 (Abcam, Cambridge, UK; $1: 200$ ). No suitable antibodies were commercially available for the rabbit $\mathrm{F}$ isoform of $\alpha$-1-antiproteinase or the rabbit collagen-I $\alpha 1$ fragment that was identified with LC-MS/MS. Following washing, the membranes were further incubated with appropriate horseradish peroxidase-conjugated secondary antibodies: P0163 sheep and P0260 mouse (both 1:1000; DAKO, Glostrup, Denmark). Proteins were visualized with the enhanced chemiluminescence system (GE Healthcare) and imaging system (Fujifilm LAS-3000, Tokyo, Japan).

\section{Results}

3.1. 2D-PAGE Analysis. Up to approximately 340 protein spots were clearly resolved on each of the $112 \mathrm{D}$ gels. Ten protein spots were found to be significantly and at least twofold differentially expressed between the sham and detachment vitreous groups (Figure 2). Three protein spots were upregulated and seven spots were downregulated.

3.2. LC-MS/MS Analysis. From the three upregulated protein spots, two were identified as fragments of albumin (spots 5104 and 6101), whilst spot 6205 could not be identified. Four of the seven downregulated protein spots were identified as fragment of collagen-I $\alpha 1$ (spot 0503), $\alpha$-1-antiproteinase F (spots 0703 and 1707), and peroxiredoxin 2 (spot 0705). Protein spots 0102,0815 , and 1302 could not be identified (Figure 2; Table 1).

3.3. Western Blot Analysis. Western blotting developed with anti-albumin showed a heavy band at approximately $60 \mathrm{kDa}$, which is likely to represent the full length protein, whilst multiple bands below this suggest the presence of several fragments, some of which may correspond with those identified with the 2D-PAGE analysis (Figure 3, left). Peroxiredoxin 2 has a deduced molecular mass of approximately $22 \mathrm{kDa}$. However, spot 0705 containing peroxiredoxin 2 migrates with a molecular mass around $60 \mathrm{kDa}$ with 2D-PAGE (Figure 2), and this size was verified by western blot analysis (Figure 3, right). Though a single and specific band was achieved with anti-peroxiredoxin 2, western blotting could not be reliably used for quantification due to a weak signal near the detection limit and variable background reaction.

\section{Discussion}

4.1. Albumin. Analysis with 2D-PAGE revealed fragments of albumin to be upregulated in the vitreous following retinal detachment. Albumin is the most abundant protein in plasma, aqueous, and vitreous humor, where in the latter it constitutes around $60-70 \%$ of total protein [19-21]. Serum proteins such as albumin are present in the aqueous and vitreous humor at a relatively lower level compared to the vascular circulation from where they may have in part originated [21, 22]. Western blot analysis showed an intense band at approximately $60 \mathrm{kDa}$ corresponding with the full length albumin 


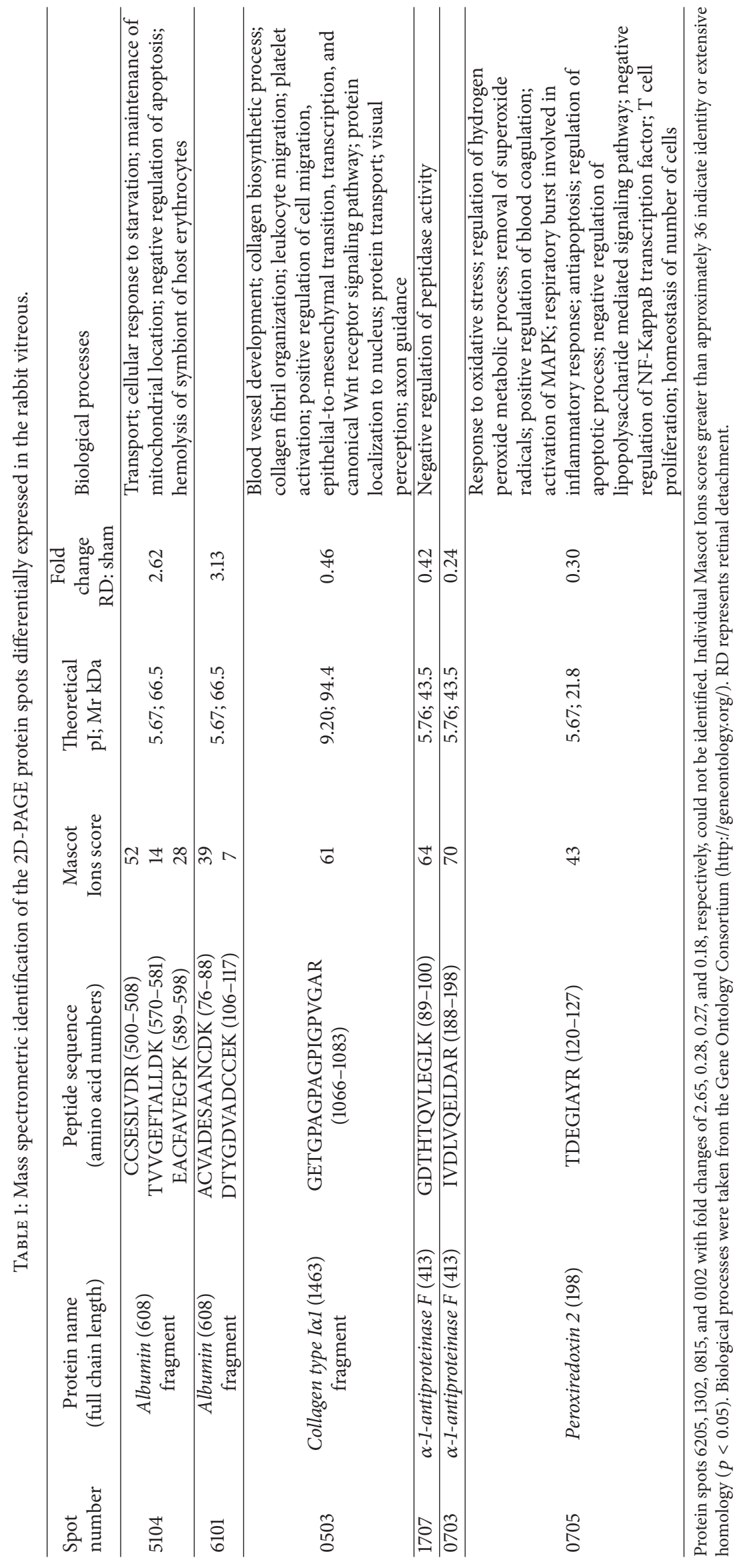




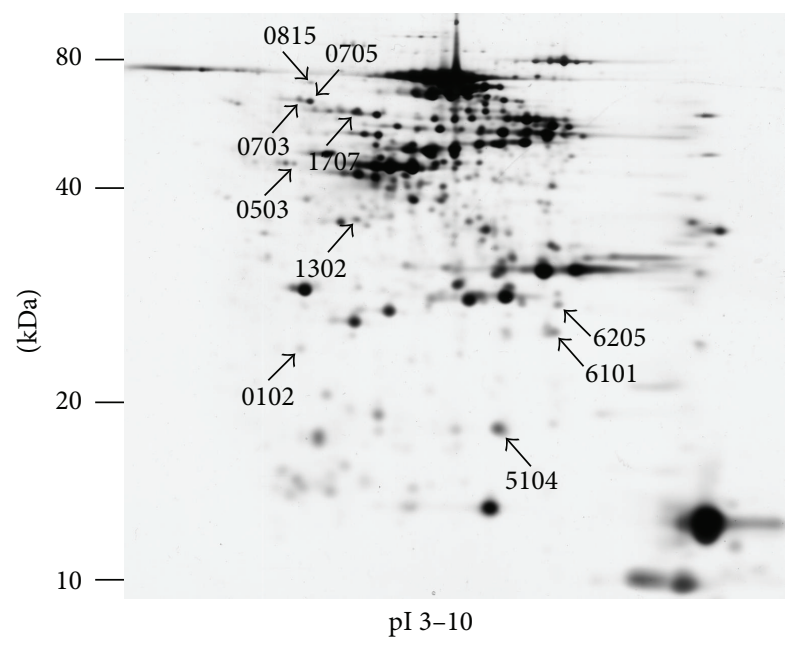

(a)

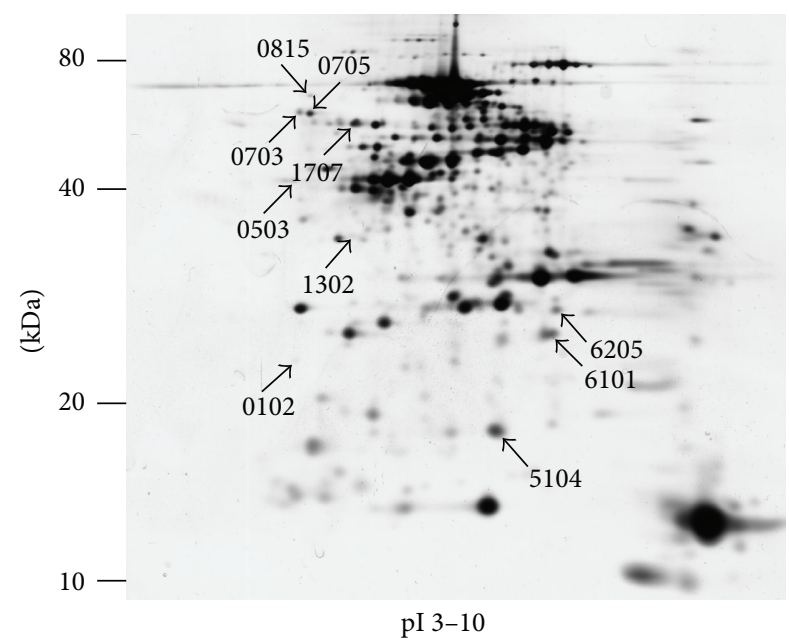

(b)

FIGURE 2: Representative 2D-PAGE images of proteins fractionated from rabbit vitreous. Ten protein spots (arrows) were found to be significantly and at least twofold differentially expressed between the sham (a) and detached (b) vitreous.

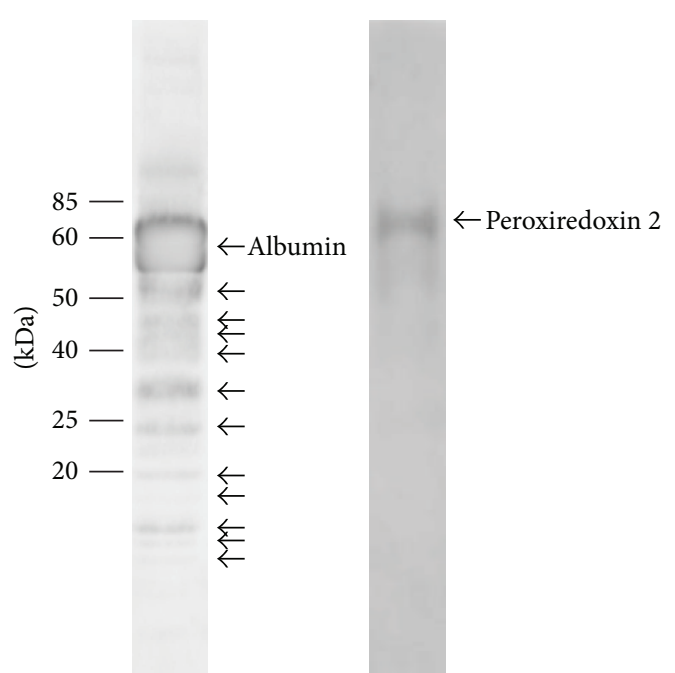

FIGURE 3: Western blot analysis of sham rabbit vitreous developed with anti-albumin and anti-peroxiredoxin 2. Labeled arrows correspond to the respective full length proteins. The unlabeled arrows for the lower molecular mass bands on the anti-albumin blot may indicate the specific cleavage fragments, which correspond with some of the differentially expressed 2D-PAGE protein spots.

protein, with multiple lower molecular mass bands that are likely its fragments. Increase of albumin and its fragments may signify increased proteolysis and the passage of albumin into the vitreous. Indeed, the breakdown of the blood-retinal barrier that occurs with retinal detachment has also been implicated in the increase of other such proteins in the vitreous [12, 23-28]. It is also possible that albumin in the vitreous may arise from de novo synthesis in the retina, similar to the reported increased gene and protein expression of albumin in the corneal epithelium during wound healing $[29,30]$.
Extraocular albumin is known to have diverse and important functions, which include maintenance of colloid osmotic pressure, transport of biomolecules, and inactivation of toxins through intermolecular binding [31,32]. Albumin can also act as an antioxidant by scavenging reactive oxygen species and sequestration of metal ions and has anti-inflammatory and apoptotic regulatory abilities [32-35]. Vitreal albumin has been proposed to transport long chain fatty acids into the lens for biosynthesis of lenticular lipids [21, 31, 36]. Indeed, albumin is likely to have many such important roles in the eye, which requires further investigation.

4.2. Peroxiredoxin 2. In the present study we observed peroxiredoxin 2 to have a molecular mass above $60 \mathrm{kDa}$ using both 2D-PAGE and western blot analyses. However, the predicted molecular mass of the peroxiredoxin family of proteins is approximately $22 \mathrm{kDa}-31 \mathrm{kDa}$. This variation may represent the well-studied property of these proteins to undergo oligomerization, which can be promoted by a number of factors including overoxidation of cysteine residues of peroxiredoxin [37]. Although the present experiments were conducted in standard reducing conditions that aim to break cysteine bonds, we obtained a band well above $20 \mathrm{kDa}$. This is in keeping with another study, which also showed some peroxiredoxin 2 western blot bands appearing at molecular mass much higher than $20 \mathrm{kDa}$ that was suggested to result from oligomerization or posttranslational modification [38]. Our finding could also represent a novel alternative splicing variant of peroxiredoxin 2, as reported for peroxiredoxin 5 [39].

The peroxiredoxins are a group of ubiquitous antioxidant proteins that currently comprise six members in mammals [40]. These proteins are primarily found at high levels intracellularly, mainly within the cytosol, but are also present in the mitochondria, peroxisomes, and nuclei, and they may be exported [37]. Furthermore, presence of peroxiredoxin 2 has been shown in plasma, not only as a result of hemolysis but 
also possibly by secretion from the T lymphocytes [41, 42]. These multifunction enzymes act as antioxidants by using redox active cysteines for the reduction and degradation of hydrogen peroxide, peroxynitrite, and organic hydroperoxides [37, 43]. Oxidative stress is thought to result from an imbalance between reactive oxygen species production and antioxidant ability and is recognized to be an important factor in the pathogenesis of a number of age-related and neurodegenerative diseases, which include age-related cataract, agerelated macular degeneration, glaucoma, diabetic retinopathy, retinal detachment, and PVR [44-47]. Indeed, the present study showed a decrease in the vitreal levels of peroxiredoxin 2 following retinal detachment. This may be in keeping with reported reductions in the levels of other members of the antioxidant defense system such as glutathione and ascorbic acid both in vitreal and in blood samples of patients suffering from PVR $[44,45]$. Furthermore, apart from their role as antioxidants, the peroxiredoxins can affect a diverse range of biological processes that include cellular proliferation, differentiation, and apoptosis by influencing signal transduction pathways that employ hydrogen peroxide as a secondary messenger $[43,48]$. Recent studies on tears from patients with glaucoma have also identified peroxiredoxin 1 as having a possible involvement in inflammation $[49,50]$. Indeed, peroxiredoxin 2 and other members of this family of proteins are liable to have a significant role in the pathophysiology of retinal detachment.

4.3. Collagen-I $\alpha 1$. A fragment of collagen-I $\alpha 1$ was identified in the vitreous of the rabbit; however, type I collagen has not previously been identified as a natural component of the mammalian vitreous and is rather known to be a constituent of early PVR membranes [51-53] and retinal blood vessels $[54,55]$. A mixture of type II, IX, and V/XI hybrid collagen fibrils, which are separated out mainly by water and ions attracted to hyaluronan, characterizes the vitreous body [56]. Collagen, possibly with the aid of adhesive-like intermediate molecules, may provide the basis of vitreoretinal adhesion by connecting the vitreous with the retinal inner limiting membrane (ILM). This attachment is extremely strong in the vitreous base since the fibrils pass through the ILM to merge into underlying collagen networks and crypts $[2,56,57]$. Collagen is also a significant component of both epiretinal and subretinal PVR membranes [53, 58], and type I collagen is recognized to be a principal constituent during their early development [51-53]. The presence of collagen in the subretinal space, a place normally devoid of this protein, suggests that certain cells, particularly the RPE and Müller cells associated with membranes, are able to synthesize collagen under certain pathological conditions such as retinal detachment and PVR [58-61]. However, the present analysis suggests collagen-I $\alpha 1$ fragment to be found in sham vitreous, which furthermore showed a decreased concentration following retinal detachment that may indicate perturbed proteolytic activity. Matrix metalloproteinases (MMP) and other proteolytic enzymes that are able to degrade and remodel vitreal collagen have been found to be increased with RRD and PVR [62-65], which could be in keeping with the decrease in $\alpha$-1-antiproteinase shown in the present study. Further studies will be necessary to confirm the source and nature of collagen-I $\alpha 1$ in the vitreous and the possible mechanisms of collagen fragmentation that may be an important feature of vitreous liquefaction and $\mathrm{RRD}[2,62,66]$.

4.4. Alpha-1-Antiproteinase. 2D-PAGE showed $\alpha$-1-antiproteinase (also called $\alpha$-1-antitrypsin or $\alpha$-1-proteinase inhibitor) at two closely positioned spots, which were largely in keeping with their predicted molecular mass but differing by their charge. Currently, four isoforms of $\alpha$-1-antiproteinase have been identified in the rabbit, termed F, S1, S2, and E, which is a similar picture to the multiple variants identified in humans $[67,68]$. Alpha-1-antiproteinase is an acute phase protein and archetypal member of the superfamily of serine protease inhibitors (serpin), which are involved in a wide range of biological processes that includes inflammation, angiogenesis, blood coagulation, ECM remodeling, and tumor suppression [69]. This protein has the ability to inhibit a large number of serine proteases though its principle target is neutrophil elastase [68]. Indeed, $\alpha$-1-antiproteinase originally received much attention because its deficiency increases the risk of a variety of clinical conditions, such as chronic obstructive pulmonary disease, which can result from unrestrained elastase activity.

We found the $\mathrm{F}$ isoform of rabbit $\alpha$-1-antiproteinase to be downregulated in the vitreous following retinal detachment. The $\mathrm{F}$ isoform of $\alpha$-1-antiproteinase is the only one of the rabbit isoforms so far identified that has been shown to have the oxidizable methionine residue site that is present in human $\alpha$-1-antiproteinase [67]. The oxidation of methionine to methionine sulfoxide, which can occur during episodes of inflammation as a result of oxygen-free radicals secreted by leucocytes, has an inhibiting effect upon $\alpha$-1-antiproteinase function. This process is thought to enhance the ability of proteinases such as elastase to locally degrade tissue debris that occurs at sites of inflammation $[67,68]$.

Alpha-1-antiproteinase is primarily produced in the liver and circulated to the rest of the body tissues via the blood; however, extrahepatic sites of its synthesis have been identified, which include blood monocytes, alveolar macrophages, bronchial and gastrointestinal epithelial cells, and the cornea [70-73]. The protein has also been localized to the tear film, aqueous humor, and vitreous, where in the latter a phosphorylated form of $\alpha$-1-antiproteinase has been suggested as a potential biomarker of idiopathic macular hole and rhegmatogenous retinal detachment [73-75]. It has been postulated that one of the main functions of corneal $\alpha$-1-antiproteinase is to protect against the damaging effects of neutrophil elastase produced during corneal inflammation [73], and it may be expected that a similar role in addition to others is applicable to vitreal $\alpha$-1-antiproteinase, though this requires further investigation.

\section{Conclusion}

This proteomic investigation of the rabbit vitreous has identified a set of proteins that assist our understanding of the pathogenesis of rhegmatogenous retinal detachment and its 
complications. Further studies will be necessary to clarify the role of these proteins. Certain proteins, such as those of low abundance and at the extremes of molecular mass, together with membrane proteins, can be difficult to resolve and detect using the 2D-PAGE technique. Therefore, complementary proteomic methods such as gel-free mass spectrometry should be considered in future work in order to help address these limitations.

\section{Disclaimer}

The authors alone are responsible for the content and writing of the paper.

\section{Conflict of Interests}

The authors report no conflict of interests.

\section{Acknowledgments}

The authors appreciate the excellent technical support provided by Mona Britt Hansen and Inge Kjærgaard and are grateful to Dr. Satpal Ahuja for the helpful suggestions for the paper. This work was supported by The Danish Society for Eye Health, The Danish Eye Research Foundation, Foreningen Østifterne, The Synoptik Foundation, The Beckett Foundation, The Danish Medical Research Council, The John and Birthe Meyer Foundation, Aarhus University Research Foundation, The National Science Foundation, USA (ITR0331697), and National Institutes of Health, USA.

\section{References}

[1] A. Sodhi, L.-S. Leung, D. V. Do, E. W. Gower, O. D. Schein, and J. T. Handa, "Recent trends in the management of rhegmatogenous retinal detachment," Survey of Ophthalmology, vol. 53, no. 1, pp. 50-67, 2008.

[2] D. Mitry, B. W. Fleck, A. F. Wright, H. Campbell, and D. G. Charteris, "Pathogenesis of rhegmatogenous retinal detachment: predisposing anatomy and cell biology," Retina, vol. 30, no. 10, pp. 1561-1572, 2010.

[3] D. Mitry, D. G. Charteris, D. Yorston et al., "The epidemiology and socioeconomic associations of retinal detachment in Scotland: a two-year prospective population-based study," Investigative Ophthalmology and Visual Science, vol. 51, no. 10, pp. 4963-4968, 2010.

[4] S. K. Fisher and G. P. Lewis, "Cellular effects of detachment and reattachment on the neural retina and the retinal pigment epithelium," in Retina, S. J. Ryan, D. R. Hinton, A. P. Schachat, and C. P. Wilkinson, Eds., vol. 3, pp. 1991-2012, Mosby, St. Louis, Mo, USA, 2006.

[5] S. Tamiya, L. Liu, and H. J. Kaplan, "Epithelial-mesenchymal transition and proliferation of retinal pigment epithelial cells initiated upon loss of cell-cell contact," Investigative Ophthalmology \& Visual Science, vol. 51, no. 5, pp. 2755-2763, 2010.

[6] S. Pennock, M.-A. Rheaume, S. Mukai, and A. Kazlauskas, "A novel strategy to develop therapeutic approaches to prevent proliferative vitreoretinopathy," The American Journal of Pathology, vol. 179, no. 6, pp. 2931-2940, 2011.
[7] N. Mandal, S. Heegaard, J. U. Prause, B. Honoré, and H. Vorum, "Ocular proteomics with emphasis on two-dimensional gel electrophoresis and mass spectrometry," Biological Procedures Online, vol. 12, no. 1, pp. 56-88, 2010.

[8] S. E. Coupland, H. Vorum, N. Mandal et al., "Proteomics of uveal melanomas suggests HSP-27 as a possible surrogate marker of chromosome 3 loss," Investigative Ophthalmology \& Visual Science, vol. 51, no. 1, pp. 12-20, 2010.

[9] N. Mandal, M. Kofod, H. Vorum et al., "Proteomic analysis of human vitreous associated with idiopathic epiretinal membrane," Acta Ophthalmologica, vol. 91, no. 4, pp. e333-e334, 2013.

[10] L. J. Cehofski, N. Mandal, B. Honoré, and H. Vorum, "Analytical platforms in vitreoretinal proteomics," Bioanalysis, vol. 6, no. 22, pp. 3051-3066, 2014.

[11] L. J. Cehofski, A. Kruse, B. Kjærgaard, A. Stensballe, B. Honoré, and H. Vorum, "Dye-free porcine model of experimental branch retinal vein occlusion: a suitable approach for retinal proteomics," Journal of Ophthalmology, vol. 2015, Article ID 839137, 7 pages, 2015.

[12] N. Mandal, G. P. Lewis, S. K. Fisher et al., "Protein changes in the retina following experimental retinal detachment in rabbits," Molecular Vision, vol. 17, pp. 2634-2648, 2011.

[13] T. Shitama, H. Hayashi, S. Noge et al., "Proteome profiling of vitreoretinal diseases by cluster analysis," Proteomics-Clinical Applications, vol. 2, no. 9, pp. 1265-1280, 2008.

[14] J. Yu, F. Liu, S.-J. Cui et al., "Vitreous proteomic analysis of proliferative vitreoretinopathy," Proteomics, vol. 8, no. 17, pp. 36673678, 2008.

[15] J. Yu, R. Peng, H. Chen, C. Cui, and J. Ba, "Elucidation of the pathogenic mechanism of rhegmatogenous retinal detachment with proliferative vitreoretinopathy by proteomic analysis," Investigative Ophthalmology and Visual Science, vol. 53, no. 13, pp. 8146-8153, 2012.

[16] M. Angi, H. Kalirai, S. E. Coupland, B. E. Damato, F. Semeraro, and M. R. Romano, "Proteomic analyses of the vitreous humour," Mediators of Inflammation, vol. 2012, Article ID 148039, 7 pages, 2012.

[17] V. B. Mahajan and J. M. Skeie, "Translational vitreous proteomics," Proteomics: Clinical Applications, vol. 8, no. 3-4, pp. 204-208, 2014.

[18] E. Mortz, T. N. Krogh, H. Vorum, and A. Görg, "Improved silver staining protocols for high sensitivity protein identification using matrix-assisted laser desorption/ionization-time of flight analysis," Proteomics, vol. 1, no. 11, pp. 1359-1363, 2001.

[19] J. N. Ulrich, M. Spannagl, A. Kampik, and A. Gandorfer, "Components of the fibrinolytic system in the vitreous body in patients with vitreoretinal disorders," Clinical and Experimental Ophthalmology, vol. 36, no. 5, pp. 431-436, 2008.

[20] K. Yamane, A. Minamoto, H. Yamashita et al., "Proteome analysis of human vitreous proteins," Molecular \& Cellular Proteomics, vol. 2, no. 11, pp. 1177-1187, 2003.

[21] J. Sabah, E. McConkey, R. Welti, K. Albin, and L. J. Takemoto, "Role of albumin as a fatty acid carrier for biosynthesis of lens lipids," Experimental Eye Research, vol. 80, no. 1, pp. 31-36, 2005.

[22] T. F. Freddo, "Shifting the paradigm of the blood-aqueous barrier," Experimental Eye Research, vol. 73, no. 5, pp. 581-592, 2001.

[23] B. C. Little and V. M. G. Ambrose, "Blood-aqueous barrier breakdown associated with rhegmatogenous retinal detachment," Eye, vol. 5, part 1, pp. 56-62, 1991. 
[24] H. Nagasaki, K. Shinagawa, and M. Mochizuki, "Risk factors for proliferative vitreoretinopathy," Progress in Retinal and Eye Research, vol. 17, no. 1, pp. 77-98, 1998.

[25] C. C. Tomé, M. V. De Rojas Silva, J. Rodríguez-García, S. Rodríguez-Segade, and M. Sánchez-Salorio, "Levels of pentosidine in the vitreous of eyes with proliferative diabetic retinopathy, proliferative vitreoretinopathy and retinal detachment," Graefe's Archive for Clinical and Experimental Ophthalmology, vol. 243, no. 12, pp. 1272-1276, 2005.

[26] R. F. Gariano, A. K. Nath, D. J. D’Amico, T. Lee, and M. R. SierraHonigmann, "Elevation of vitreous leptin in diabetic retinopathy and retinal detachment," Investigative Ophthalmology and Visual Science, vol. 41, no. 11, pp. 3576-3581, 2000.

[27] G. E. Rose, B. M. Billington, and A. H. Chignell, "Immunoglobulins in paired specimens of vitreous and subretinal fluids from patients with rhegmatogenous retinal detachment," The British Journal of Ophthalmology, vol. 74, no. 3, pp. 160-162, 1990.

[28] J. E. Pederson and C. B. Toris, "Experimental retinal detachment. IX. Aqueous, vitreous, and subretinal protein concentrations," Archives of Ophthalmology, vol. 103, no. 6, pp. 835-836, 1985.

[29] L. Carter-Dawson, Y. Zhang, R. S. Harwerth et al., "Elevated albumin in retinas of monkeys with experimental glaucoma," Investigative Ophthalmology \& Visual Science, vol. 51, no. 2, pp. 952-959, 2010.

[30] S. Mushtaq, Z. A. Naqvi, A. A. Siddiqui, C. Palmberg, J. Shafqat, and N. Ahmed, "Changes in albumin precursor and heat shock protein 70 expression and their potential role in response to corneal epithelial wound repair," Proteomics, vol. 7, no. 3, pp. 463-468, 2007.

[31] T. Peters, All About Albumin: Biochemistry, Genetics, and Medical Applications, Academic Press, San Diego, Calif, USA, 1996.

[32] G. J. Quinlan, G. S. Martin, and T. W. Evans, "Albumin: biochemical properties and therapeutic potential," Hepatology, vol. 41, no. 6, pp. 1211-1219, 2005.

[33] C. Bolitho, P. Bayl, J. Y. Hou et al., "The anti-apoptotic activity of albumin for endothelium is mediated by a partially cryptic protein domain and reduced by inhibitors of G-coupled protein and PI-3 kinase, but is independent of radical scavenging or bound lipid," Journal of Vascular Research, vol. 44, no. 4, pp. 313324, 2007.

[34] E. Erkan, P. Devarajan, and G. J. Schwartz, "Mitochondria are the major targets in albumin-induced apoptosis in proximal tubule cells," Journal of the American Society of Nephrology, vol. 18, no. 4, pp. 1199-1208, 2007.

[35] J. Iglesias, V. E. Abernethy, Z. Wang, W. Lieberthal, J. S. Koh, and J. S. Levine, "Albumin is a major serum survival factor for renal tubular cells and macrophages through scavenging of ROS," The American Journal of Physiology - Renal Physiology, vol. 277, no. 5, pp. F711-F722, 1999.

[36] J. R. Sabah, H. Davidson, E. N. McConkey, and L. Takemoto, "In vivo passage of albumin from the aqueous humor into the lens," Molecular Vision, vol. 10, pp. 254-259, 2004.

[37] Z. A. Wood, E. Schröder, J. R. Harris, and L. B. Poole, "Structure, mechanism and regulation of peroxiredoxins," Trends in Biochemical Sciences, vol. 28, no. 1, pp. 32-40, 2003.

[38] G. Manandhar, A. Miranda-Vizuete, J. R. Pedrajas et al., "Peroxiredoxin 2 and peroxidase enzymatic activity of mammalian spermatozoa," Biology of Reproduction, vol. 80, no. 6, pp. 1168$1177,2009$.

[39] M. Sensi, G. Pietra, A. Molla et al., "Peptides with dual binding specificity for HLA-A2 and HLA-E are encoded by alternatively spliced isoforms of the antioxidant enzyme peroxiredoxin 5," International Immunology, vol. 21, no. 3, pp. 257-268, 2009.

[40] G. Leyens, I. Donnay, and B. Knoops, "Cloning of bovine peroxiredoxins-gene expression in bovine tissues and amino acid sequence comparison with rat, mouse and primate peroxiredoxins," Comparative Biochemistry and Physiology B Biochemistry and Molecular Biology, vol. 136, no. 4, pp. 943-955, 2003.

[41] J.-H. Chen, Y.-W. Chang, C.-W. Yao et al., "Plasma proteome of severe acute respiratory syndrome analyzed by twodimensional gel electrophoresis and mass spectrometry," Proceedings of the National Academy of Sciences of the United States of America, vol. 101, no. 49, pp. 17039-17044, 2004.

[42] J. Fujii and Y. Ikeda, "Advances in our understanding of peroxiredoxin, a multifunctional, mammalian redox protein," Redox Report, vol. 7, no. 3, pp. 123-130, 2002.

[43] S. Immenschuh and E. Baumgart-Vogt, "Peroxiredoxins, oxidative stress, and cell proliferation," Antioxidants and Redox Signaling, vol. 7, no. 5-6, pp. 768-777, 2005.

[44] E. Cicik, H. Tekin, S. Akar et al., "Interleukin-8, nitric oxide and glutathione status in proliferative vitreoretinopathy and proliferative diabetic retinopathy," Ophthalmic Research, vol. 35, no. 5, pp. 251-255, 2003.

[45] S. Takano, S. Ishiwata, M. Nakazawa, M. Mizugaki, and M. Tamai, "Determination of ascorbic acid in human vitreous humor by high-performance liquid chromatography with UV detection," Current Eye Research, vol. 16, no. 6, pp. 589-594, 1997.

[46] M. Cederlund, F. Ghosh, K. Arnér, S. Andréasson, and B. Åkerström, "Vitreous levels of oxidative stress biomarkers and the radical-scavenger $\alpha_{1}$-microglobulin/A1M in human rhegmatogenous retinal detachment," Graefe's Archive for Clinical and Experimental Ophthalmology, vol. 251, no. 3, pp. 725-732, 2013.

[47] D. N. Zacks, Y. Han, Y. Zeng, and A. Swaroop, "Activation of signaling pathways and stress-response genes in an experimental model of retinal detachment," Investigative Ophthalmology and Visual Science, vol. 47, no. 4, pp. 1691-1695, 2006.

[48] Z. A. Wood, L. B. Poole, and P. A. Karplus, "Peroxiredoxin evolution and the regulation of hydrogen peroxide signaling," Science, vol. 300, no. 5619, pp. 650-653, 2003.

[49] D. Pieragostino, S. Bucci, L. Agnifili et al., "Differential protein expression in tears of patients with primary open angle and pseudoexfoliative glaucoma," Molecular BioSystems, vol. 8, no. 4, pp. 1017-1028, 2012.

[50] D. Pieragostino, L. Agnifili, V. Fasanella et al., "Shotgun proteomics reveals specific modulated protein patterns in tears of patients with primary open angle glaucoma naïve to therapy," Molecular BioSystems, vol. 9, no. 6, pp. 1108-1116, 2013.

[51] D. G. Charteris, "Proliferative vitreoretinopathy: pathobiology, surgical management, and adjunctive treatment," British Journal of Ophthalmology, vol. 79, no. 10, pp. 953-960, 1995.

[52] M. Jin, S. He, V. Worpel, S. J. Ryan, and D. R. Hinton, "Promotion of adhesion and migration of RPE cells to provisional extracellular matrices by TNF- $\alpha$, Investigative Ophthalmology and Visual Science, vol. 41, no. 13, pp. 4324-4332, 2000.

[53] J. A. Jerdan, J. S. Pepose, R. G. Michels et al., "Proliferative vitreoretinopathy membranes. An immunohistochemical study," Ophthalmology, vol. 96, no. 6, pp. 801-810, 1989.

[54] T. Ihanamäki, L. J. Pelliniemi, and E. Vuorio, "Collagens and collagen-related matrix components in the human and mouse eye," Progress in Retinal and Eye Research, vol. 23, no. 4, pp. 403434, 2004. 
[55] J. A. Jerdan and B. M. Glaser, "Retinal microvessel extracellular matrix: an immunofluorescent study," Investigative Ophthalmology \& Visual Science, vol. 27, no. 2, pp. 194-203, 1986.

[56] M. M. Le Goff and P. N. Bishop, "Adult vitreous structure and postnatal changes," Eye, vol. 22, no. 10, pp. 1214-1222, 2008.

[57] S. Heegaard, O. A. Jensen, and J. U. Prause, "Structure and composition of the inner limiting membrane of the retina. SEM on frozen resin-cracked and enzyme-digested retinas of Macacca mulatta," Graefe's Archive for Clinical and Experimental Ophthalmology, vol. 224, no. 4, pp. 355-360, 1986.

[58] H. Laqua, "Collagen formation by periretinal cellular membranes," Developments in Ophthalmology, vol. 2, pp. 396-406, 1981.

[59] P. Hiscott, C. Sheridan, R. M. Magee, and I. Grierson, "Matrix and the retinal pigment epithelium in proliferative retinal disease," Progress in Retinal and Eye Research, vol. 18, no. 2, pp. 167-190, 1999.

[60] I. Morino, P. Hiscott, N. McKechnie, and I. Grierson, "Variation in epiretinal membrane components with clinical duration of the proliferative tissue," British Journal of Ophthalmology, vol. 74, no. 7, pp. 393-399, 1990.

[61] T. L. Ponsioen, M. J. A. van Luyn, R. J. van der Worp, H. H. Pas, J. M. M. Hooymans, and L. I. Los, "Human retinal Müller cells synthesize collagens of the vitreous and vitreoretinal interface in vitro," Molecular Vision, vol. 14, pp. 652-660, 2008.

[62] M. van Deemter, H. H. Pas, R. Kuijer, R. J. van der Worp, J. M. M. Hooymans, and L. I. Los, "Enzymatic breakdown of type II collagen in the human vitreous," Investigative Ophthalmology and Visual Science, vol. 50, no. 10, pp. 4552-4560, 2009.

[63] C. Symeonidis, E. Diza, E. Papakonstantinou, E. Souliou, S. A. Dimitrakos, and G. Karakiulakis, "Correlation of the extent and duration of rhegmatogenous retinal detachment with the expression of matrix metalloproteinases in the vitreous," Retina, vol. 27, no. 9, pp. 1279-1285, 2007.

[64] C. H. Kon, N. L. Occleston, D. Charteris, J. Daniels, G. W. Aylward, and P. T. Khaw, "A prospective study of matrix metalloproteinases in proliferative vitreoretinopathy," Investigative Ophthalmology and Visual Science, vol. 39, no. 8, pp. 1524-1529, 1998.

[65] C. Symeonidis, E. Papakonstantinou, E. Souliou, G. Karakiulakis, S. A. Dimitrakos, and E. Diza, "Correlation of matrix metalloproteinase levels with the grade of proliferative vitreoretinopathy in the subretinal fluid and vitreous during rhegmatogenous retinal detachment," Acta Ophthalmologica, vol. 89, no. 4, pp. 339-345, 2011.

[66] L. I. Los, R. J. van der Worp, M. J. A. van Luyn, and J. M. M. Hooymans, "Age-related liquefaction of the human vitreous body: LM and TEM evaluation of the role of proteoglycans and collagen," Investigative Ophthalmology and Visual Science, vol. 44, no. 7, pp. 2828-2833, 2003.

[67] A. Saito and H. Sinohara, "Various forms of rabbit plasma $\alpha$ 1-antiproteinase," Biochemistry and Molecular Biology International, vol. 46, no. 1, pp. 27-34, 1998.

[68] S. D. Patterson, "Mammalian $\alpha_{1}$-antitrypsins: comparative biochemistry and genetics of the major plasma serpin," Comparative Biochemistry and Physiology Part B: Comparative Biochemistry, vol. 100, no. 3, pp. 439-454, 1991.

[69] G. A. Silverman, P. I. Bird, R. W. Carrell et al., "The serpins are an expanding superfamily of structurally similar but functionally diverse proteins. Evolution, mechanism of inhibition, novel functions, and a revised nomenclature," The Journal of Biological Chemistry, vol. 276, no. 36, pp. 33293-33296, 2001.
[70] D. H. Perlmutter, F. S. Cole, P. Kilbridge, T. H. Rossing, and H. R. Colten, "Expression of the alpha 1-proteinase inhibitor gene in human monocytes and macrophages," Proceedings of the National Academy of Sciences of the United States of America, vol. 82, no. 3, pp. 795-799, 1985.

[71] J. Cichy, J. Potempa, and J. Travis, "Biosynthesis of $\alpha 1$-proteinase inhibitor by human lung-derived epithelial cells," Journal of Biological Chemistry, vol. 272, no. 13, pp. 8250-8255, 1997.

[72] D. Faust, K. Raschke, S. Hormann, V. Milovic, and J. Stein, "Regulation of $\alpha 1$-proteinase inhibitor release by proinflammatory cytokines in human intestinal epithelial cells," Clinical and Experimental Immunology, vol. 128, no. 2, pp. 279-284, 2002.

[73] S. S. Twining, T. Fukuchi, B. Y. J. T. Yue, P. M. Wilson, and G. Boskovic, "Corneal synthesis of $\alpha 1$-proteinase inhibitor ( $\alpha 1$ antitrypsin)," Investigative Ophthalmology and Visual Science, vol. 35, no. 2, pp. 458-462, 1994.

[74] M. Funding, H. Vorum, E. Nexø, and N. Ehlers, "Alpha-1antitrypsin in aqueous humour from patients with corneal allograft rejection," Acta Ophthalmologica Scandinavica, vol. 83, no. 3, pp. 379-384, 2005.

[75] N. Mukai, T. Nakanishi, A. Shimizu, T. Takubo, and T. Ikeda, "Identification of phosphotyrosyl proteins in vitreous humours of patients with vitreoretinal diseases by sodium dodecyl sulphate-polyacrylamide gel electrophoresis/Western blotting/ matrix-assisted laser desorption time-of-flight mass spectrometry," Annals of Clinical Biochemistry, vol. 45, no. 3, pp. 307-312, 2008. 


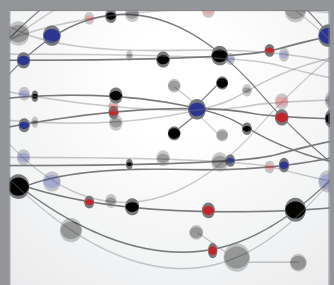

The Scientific World Journal
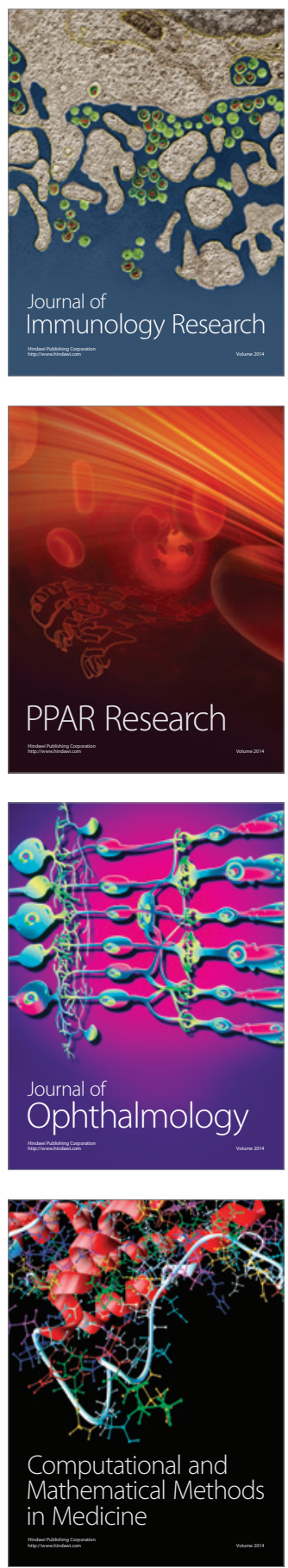

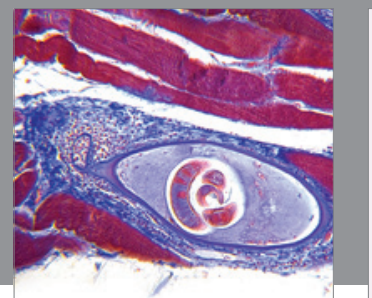

Gastroenterology

Research and Practice
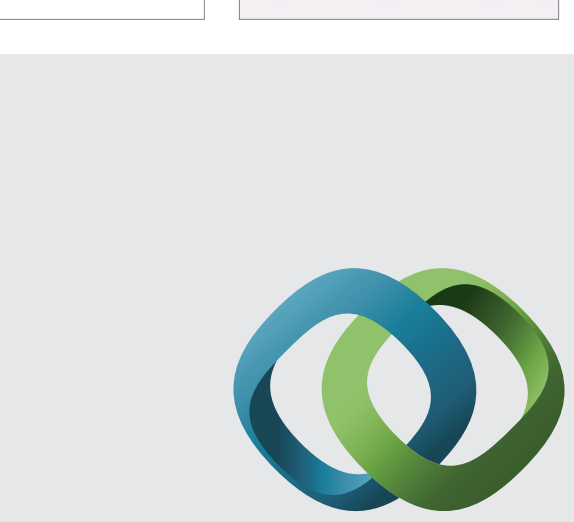

\section{Hindawi}

Submit your manuscripts at

http://www.hindawi.com
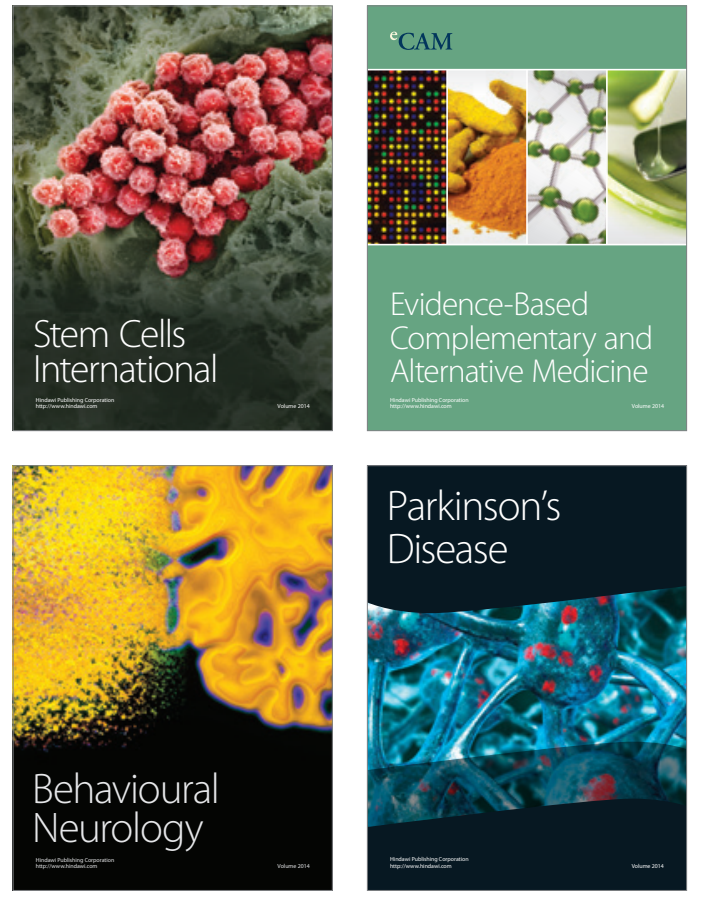
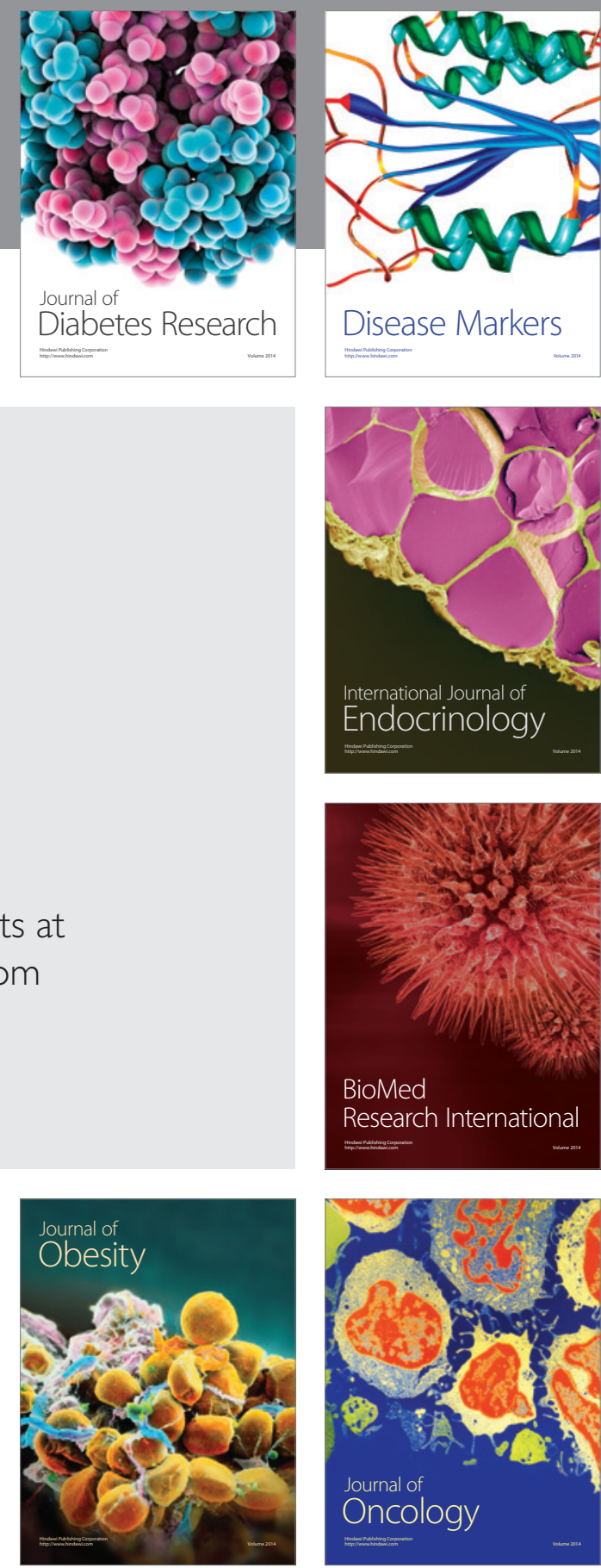

Disease Markers
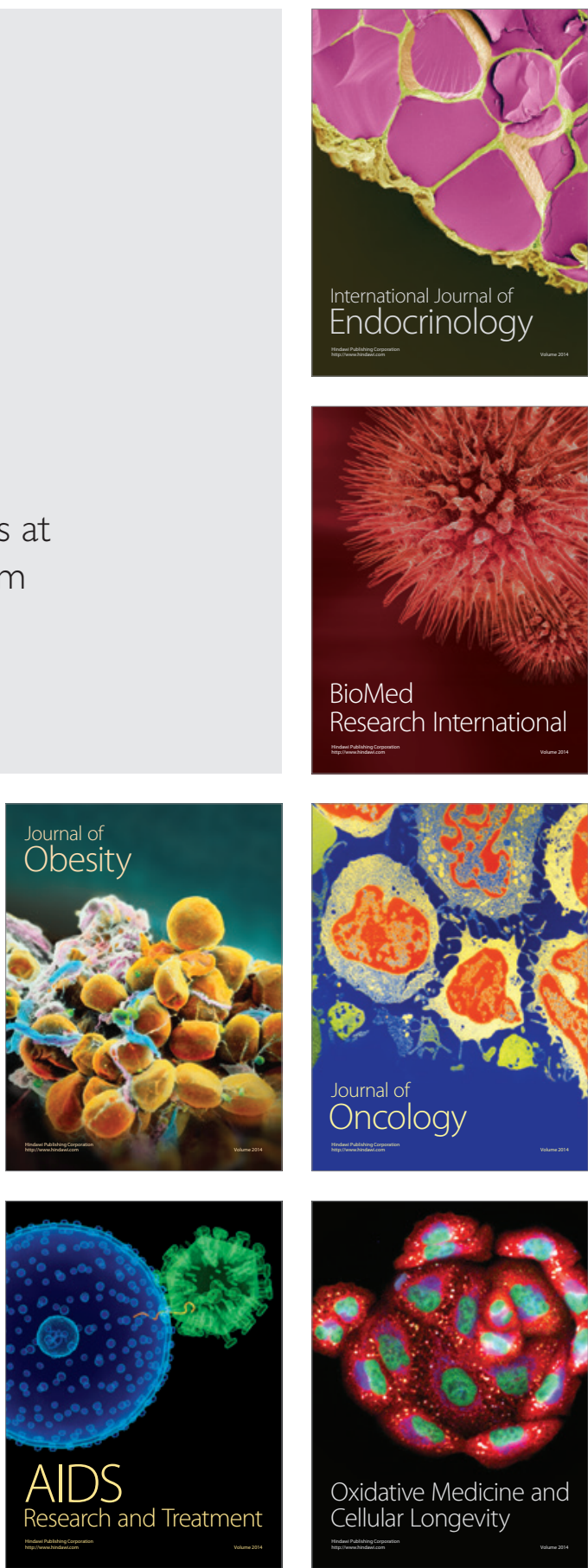